\title{
Retrieving Global Wilson Currents from Electrified Clouds Using Satellite Passive Microwave Observations
}

\author{
Michael PETERSON ${ }^{\mathrm{a}}$ \\ National Center for Atmospheric Research, Boulder, Colorado \\ WIEBKE DEIERLING \\ University of Colorado Boulder, Boulder, Colorado \\ Chuntao LiU \\ Texas A\&M University-Corpus Christi, Corpus Christi, Texas \\ DOUGLAS MACH \\ Global Hydrology and Climate Center, University of Alabama in Huntsville, Huntsville, Alabama \\ CHRISTINA KALB \\ National Center for Atmospheric Research, Boulder, Colorado
}

(Manuscript received 8 March 2018, in final form 16 May 2018)

\begin{abstract}
High-altitude atmospheric electricity measurements have been used to calculate the conduction (Wilson) currents that are supplied to the global electric circuit (GEC) by individual electrified clouds. Quantifying the global average current and assessing its temporal variability is a challenge, however, because it requires measurements in every stormy region of the world. Thus, a retrieval algorithm has been developed to infer the electric fields and Wilson currents above electrified weather from NASA ER-2 passive microwave highaltitude aircraft observations that are also common satellite products.

This study documents the adaptation of the passive microwave electric field and the Wilson current retrieval algorithm for use with satellite platforms. Three distinct variants on the algorithm are produced to respond to specific use cases that differ in 1) whether swath or microwave feature data are available to describe the lateral extent of electrified clouds, 2) the availability of coincident radar data to characterize the vertical structure of electrified clouds, and 3) the prioritization of scientific accuracy or computational expense and product latency. The Wilson currents produced by the satellite retrievals are compared with each other and also with coincident lightning measurements and the Carnegie curve. The advantages, caveats, and limitations of each variant are discussed.
\end{abstract}

\section{Introduction}

The global electric circuit (GEC) describes a series of electrical connections within the Earth system that maintains the electrical potential of the ionosphere

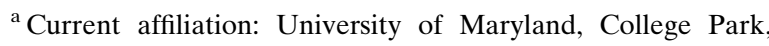
College Park, Maryland.
}

Corresponding author: Michael Peterson, michaeljp24@ gmail.com relative to Earth's surface (Adlerman and Williams 1996; Markson 2007). The GEC is powered by conduction currents (Wilson currents; Wilson 1921) generated by electrified weather across the globe. The load on the circuit from the fair-weather atmosphere responds to variations in the generator current supplied by global electrified weather. Changes in the global integrated generator current resulting from solar heating as Earth rotates create a pronounced climatological diurnal cycle in the fair-weather electric field known as the Carnegie curve (Brooks 1925; Whipple 1929; Whipple and Scrase 1936; 
Israel 1973). The distinct shape of the Carnegie curve changes throughout the year as a result of the uneven distribution of land north and south of the equator (Burns et al. 2017).

Measuring changes to the circuit load can be accomplished with a single well-sited ground station or research vessel, but quantifying differing contributions to the supply side of the circuit requires frequent global measurements of all types of electrified weather. This includes electrified shower clouds (ESCs; Wilson 1921), which are difficult to detect because they do not initiate lightning. Wilson current contributions to the GEC from individual thunderstorms and ESCs have been quantified using the Lighting Instrument Package (LIP; Bateman et al. 2007) measurements taken by the NASA ER-2 high-altitude aircraft (Mach et al. 2009). LIP consists of multiple electric field mills positioned throughout the aircraft fuselage as well as an atmospheric conductivity probe. These combined measurements at the nominal $20-\mathrm{km}$ ER-2 cruising altitude make it possible to calculate the Wilson current density, which is then integrated spatially to infer the total Wilson current supplied by the storm.

Aircraft measurements are limited to a collection of field campaign overflights, however, that tend to occur in certain key regions of the globe and often have a focus on a particular type of storm. They are not well suited for constructing a representative sample of all types of electrified clouds on global scales. For this reason, remote satellite and long-range ground-based measurements have been used to approximate the composition and overall behavior of the generator current that supplies the GEC. Mach et al. (2011) used ER-2 overflight electric fields to modify the diurnal cycle of total lightning provided by the Lightning Imaging Sensor (LIS) and Optical Transient Detector (OTD) orbital lightning imagers (Bailey et al. 2007; Blakeslee et al. 1999; Cecil et al. 2014) to account for Wilson current contributions from ESCs. Similarly, Hutchins et al. (2014) and Mezuman et al. (2014) each used ER-2 measurements to add ESC contributions to their diurnal cycles of World Wide Lightning Location Network (WWLLN) thunderstorm clusters. Liu et al. (2010), meanwhile, identified thunderstorms and ESCs in precipitation feature (PF; Nesbitt et al. 2000; Liu et al. 2008) data and then used the near-surface rainfall produced by these storm features as a proxy for Wilson current.

Reasonable agreements between these lightningbased and rainfall-based proxies and the Carnegie curve provide evidence that the global total generator current is linked to microphysical processes in electrified weather. However, while this exercise in comparisons with the fair-weather electric field measured at ground level is useful for quantifying how the global distribution of electrified weather drives the GEC, it does not draw direct connections between microphysics, electrification, and the generation of Wilson current in individual storms.

To this end, Peterson et al. (2015) developed a retrieval algorithm from ER-2 overflight data that estimates the electric field that would be measured by the LIP field mills from the spatial distribution of Advanced Microwave Precipitation Radiometer (AMPR; Spencer et al. 1994) 37- or 85-GHz passive microwave brightness temperatures. As with the LIP electric field measurements, multiplying the retrieved electric fields by the atmospheric conductivity yields an estimate of the Wilson current density across the AMPR swath. The total Wilson current for an ER-2 overpass can then be quantified by integrating the retrieved current density geospatially.

Passive microwave measurements at 37 and $85 \mathrm{GHz}$ are commonly available on satellite platforms in lowEarth orbit. The Global Precipitation Measurement (GPM) constellation, for example, consists of 10 partner satellites with intercalibrated measurements in the $85-91-\mathrm{GHz}$ band (Wilheit et al. 2015) that complete a combined $\sim 140$ orbits daily. If the ER-2 retrieval can be successfully adapted to general satellite passive microwave datasets, then the level of coverage provided by such orbital systems would allow for an unprecedented direct comparison between Wilson currents retrieved from global electrified weather and the measured fair-weather electric field in Antarctica (Burns et al. 2017) at a regular interval. Additionally, the multiple decade passive microwave record provided by the Special Sensor Microwave Imager (SSM/I: Hollinger 1991) could shed light on the long-term variability of the generator current that supplies the GEC.

This study documents the adaptation of the Peterson et al. (2015) passive microwave electric field and Wilson current retrieval algorithm for satellite datasets. Example use cases include gauging the lightning threat from electrified weather, and constructing long-term climatologies and near-real-time analyses of global thunderstorms and ESCs. A single-satellite algorithm would be ill-equipped to respond to this wide array of applications and the diverse collection of passive microwave sensors in orbit. Thus, three variants on the Peterson et al. (2015) algorithm are presented that balance the availability of geospatial data to describe the three-dimensional extent of electrified clouds with the computational expense of the algorithm. The currents retrieved from satellite observations are quantified herein and compared for each of these "forks" in the satellite algorithm codebase. 


\section{Data and methodology}

Developing a satellite version of the Peterson et al. (2015) algorithm opens the retrieval to use cases that are not possible with aircraft overflight data. However, a single unified algorithm would be unable to account for the range of computational constraints, data types, and potential applications. Thus, we divide our development into three forks, with each one leveraging the Peterson et al. (2015) algorithm to fulfill specific balances of scientific accuracy, ancillary data availability, and computational efficiency. While all forks share a common core premise and are derived from the same ER-2 collocated AMPR and LIP dataset from Peterson et al. (2015), the codebase in each fork is treated independently from the others to satisfy its specific role.

Section 2a documents the common underlying ER-2 data that are used by the aircraft and satellite versions of the electric field and the Wilson current retrieval algorithm. Section 2b describes the Peterson et al. (2015) ER-2 algorithm on which the satellite algorithm is based. Finally, section $2 \mathrm{c}$ discusses the motivations behind each fork of the satellite algorithm and highlights the differences between them.

\section{a. The ER-2 algorithm basis dataset}

This study uses the ER-2 algorithm basis dataset from Peterson et al. (2015) with a few notable improvements in artifact removal and cloud type identification. These changes affect the underlying data but not the computations in the Peterson et al. (2015) algorithm. As in Peterson et al. (2015), we resample the LIP electric field measurements to the AMPR scan interval, removing LIP lightning spikes and instrument drift from charging on the aircraft, and then integrate the LIP measurements into the AMPR record at one LIP electric field sample per AMPR scan. The result is a time-matched collocated dataset for both ER-2 instruments. Four field projects are considered: the third and the fourth Convection and Moisture Experiments (CAMEX-3 and CAMEX-4, respectively; Kakar et al. 2006), the Tropical Cloud Systems and Processes (TCSP) mission (Halverson et al. 2007), and the Tropical Rainfall Measuring Mission Large-Scale Biosphere-Atmosphere Experiment (TRMM-LBA; Halverson and Rickenbach 2002). The combined dataset includes over 200000 points of comparison between the AMPR scene below the ER-2 and the LIP electric field measured at the aircraft position.

One of the challenges of working with the AMPR passive microwave data is that cold brightness temperatures over the ocean surface introduce artifacts that resemble cold cloud regions. These ocean surface artifacts were a significant source of error in Peterson et al. (2015). The retrieval works with passive microwave brightness temperatures exclusively over electrified clouds and does not handle surface artifacts well. Even a few contaminated pixels cause errors in the retrieved electric fields that become spread over a large area. Thus, it is necessary to apply a strict filter over the ocean to remove as many artifacts as possible before the AMPR data are passed to the retrieval. In Peterson et al. (2015), we were able to identify individual oceanic cases without notable surface artifact contamination, and in these cases the retrieval was shown to produce electric field estimates that agree with LIP.

To reduce the number of ocean cases that are impacted by surface artifacts, we have developed an improved surface feature filter that removes thousands of clear-air ocean pixels and all of the identifiable false cloud features from the ER-2 dataset. The filter consists of two components. First, a mask is applied to identify oceanic regions where the $10-\mathrm{GHz}$ AMPR brightness temperature is below $160 \mathrm{~K}$ and the $37-\mathrm{GHz}$ brightness temperature is below $215 \mathrm{~K}$. These regions are flagged as possible ocean surface artifacts. Next, microwave features are constructed that bound contiguous oceanic regions in the AMPR swath that are either flagged as ocean surface artifacts or have $85-\mathrm{GHz}$ brightness temperatures above $270 \mathrm{~K}$. These features may include combinations of clear-air regions and nonconvective portions of electrified oceanic clouds. Any such oceanic feature $>500 \mathrm{~km}^{2}$ in size is considered to be contaminated by the ocean surface and removed from the sample.

We emulate the scan geometry of an orbital passive microwave sensor by regridding the high-resolution AMPR brightness temperatures to the spatial resolution of the $85-\mathrm{GHz}$ channel of the TRMM Microwave Imager (TMI) at 5-km cross track and 7-km down track (Kummerow et al. 1998). LIP measurements are also regridded by recording the average electric field in each larger pixel. The purpose of this regridding is to use the large volume of AMPR measurements rather than a small number of coincident TRMM overpasses to determine coefficients in the Peterson et al. (2015) algorithm that are compatible with the TMI scan geometry.

\section{b. The Peterson et al. (2015) ER-2 algorithm}

The passive microwave electric field retrieval algorithm from Peterson et al. (2015) uses the AMPR 37- or $85-\mathrm{GHz}$ observations of clouds below the aircraft to estimate the electric field that is measured by LIP at the ER-2 location and cruising altitude (nominally $20 \mathrm{~km}$ ). The premise of the algorithm stems from the role of ice in cloud electrification. According to noninductive 
charging (NIC; Reynolds et al. 1957; Takahashi 1978; Jayaratne et al. 1983; Saunders et al. 1991; Saunders and Peck 1998; Takahashi and Miyawaki 2002; Mansell et al. 2005), electrons are transferred between small ice particles and large graupel pellets rimed with supercooled liquid water when they collide. The small ice particles typically lose electrons to the graupel pellets. When they are lofted by the convective updraft and collect near the top of the cloud, the small ice particles create an upperlevel positive charge region. The negatively charged graupel pellets, meanwhile, remain near in the midlevels of the storm. This results in a dipole charge structure that generates Wilson current.

Real-world charge structures are more complicated than this simple dipole model (i.e., Williams et al. 1989). However, we still assume that the more ice that exists in a storm cloud, the greater the potential for collisions and charge transfer, resulting in stronger $20-\mathrm{km}$ electric fields and Wilson currents. Passive microwave observations at 37 and $85 \mathrm{GHz}$ are diagnostic of column-integrated ice water path (Vivekanandan et al. 1991). Thus, the algorithm supposes that passive microwave observations at these frequencies are related to ice content, ice content to charging, and charging to electric field and Wilson current generation. Evidence for connections between passive microwave measurements and the thunderstorm electrification can be found in another consequence of charge separation: lightning activity. Total lightning production has been repeatedly linked to passive microwave measurements in LIS and TMI measurements on the TRMM satellite (Toracinta et al. 2002; Liu et al. 2011; Prigent et al. 2005; Blyth et al. 2001; Cecil et al. 2005).

The Peterson et al. (2015) algorithm computes the electric field across the passive microwave swath in a series of three processing steps. The first step is to approximate the geospatial distribution of charge from the passive microwave data. This is accomplished by using the passive microwave brightness temperature in each cloud pixel as a proxy for charge separation. Each pixel is assigned a charge whose strength is based on the local brightness temperature. Peterson et al. (2015) considered multiple proxy functions for charging and found that a second-power polynomial for this relationship was able to best capture how the electric fields change relative to the passive microwave brightness temperatures between weak ESCs and intense thunderstorms. The charging proxy function $(f)$ is defined as follows:

$$
f=\left(T_{b_{\mathrm{env}}}-T_{b}\right)^{n}
$$

where $T_{b_{\text {env }}}$ is the brightness temperature of the environment outside of the cloud region, $T_{b}$ is the brightness temperature of the pixel of interest, and $n=2$. The environmental temperature is arbitrary, but the selected value will affect the coefficients derived in the third processing step. We do not define empirical coefficients at this stage since this relation is a proxy still in passive microwave brightness temperature units $\left(\mathrm{K}^{2}\right)$. We generally use a value of $300 \mathrm{~K}$ for the environmental temperature.

Computational constraints and a lack of information on the vertical charge distribution of the overflown storms motivated Peterson et al. (2015) to simplify the algorithm's model of electrified cloud charge structure using a single layer of net charges. Ideally, each AMPR pixel would contain a positive charge nearer to the aircraft and a lower negative charge, and these two charges would generate a net positive electric field at the aircraft location. Instead, a single net positive charge is placed near the top of the radar graupel signature that separates the small ice particles above from the graupel below. Three-dimensional radar data are not available for most ER-2 overflights, however. In these cases, the heights of the net charges are assigned using a lookup table that provides the mean 30-dBZ echo-top height in TRMM Precipitation Radar (PR) measurements associated with a specified TMI brightness temperature. Though 85-GHz brightness temperatures and 30-dBZ echo-top heights are both diagnostic of convective vigor, it is important to note that the relationship between these two parameters is not unique (Toracinta et al. 2002). We account for such differences by creating separate lookup tables for land and ocean storms. The assigned altitudes range from 8 to $14 \mathrm{~km}$.

Once the charge distribution is approximated, the second processing step applies Coulomb's law to create a proxy for the full three-dimensional electric field vector at each grid point across the passive microwave swath. For each individual pixel, the electric field contribution from every surrounding net charge is calculated based on its approximate strength from Eq. (1) and the distance between the charge and the observer. The results are then integrated to approximate the net electric field vector that would be measured at that position and the ER-2 altitude.

The final step is to estimate the measured electric field from the proxy electric field vector. To do this, electric field proxy values at the ER-2 location in each AMPR scan are compared with their counterparts in the LIP measurements. A total of 200000 points of comparison between the two instruments are used to construct a transfer function that provides the best fit to the recorded LIP data. However, the transfer function depends on the passive microwave scan geometry and must be recomputed for radiometers that have 
different pixel sizes. The transfer function for AMPR at its native resolution is

$$
E_{\mathrm{est}}\left(\mathrm{V} \mathrm{m}^{-1}\right)=0.0118 \times\left[E_{\text {proxy }}\left(\mathrm{K}^{2} \mathrm{~m}^{-2}\right)\right]^{1.0254},
$$

where $E_{\text {est }}$ is the estimated electric field $\left(\mathrm{V} \mathrm{m}^{-1}\right)$ and $E_{\text {proxy }}$ is the proxy electric field $\left(\mathrm{K}^{2} \mathrm{~m}^{-2}\right)$ from Eq. (1). The transfer function for the TMI $85-\mathrm{GHz}$ channel is

$$
E_{\text {est }}\left(\mathrm{V} \mathrm{m}^{-1}\right)=0.945 \times\left[E_{\text {proxy }}\left(\mathrm{K}^{2} \mathrm{~m}^{-2}\right)\right]^{1.0728} .
$$

Figure 1 shows how the Peterson et al. (2015) algorithm is applied to an ER-2 overflight case. The $85-\mathrm{GHz}$ cold cloud features in the AMPR swath that serve as input data for the algorithm are depicted in Fig. $1 \mathrm{~b}$ at the native AMPR resolution and in Fig. $1 \mathrm{~b}$ regridded to the resolution of the TMI. Each of the convective features in Fig. 1a contains dozens of high-resolution AMPR pixels with minimum brightness temperatures as low as $160 \mathrm{~K}$. By contrast, the convective features in the coarse TMI grid in Fig. 1b are divided between a handful of pixels. Minimum brightness temperatures are $\sim 50 \mathrm{~K}$ warmer in Fig. $1 \mathrm{~b}$ because the TMI pixels contain both convective and clear-air AMPR pixels. The transfer function in Eq. (3) takes into account the reduced pixel counts and beamfilling effects to produce the best overall match to the LIP measurements at the lower spatial resolution.

The retrieved electric fields along the ER-2 flight track (solid thick line in Figs. 1a,b) are compared with LIP in Fig. 1c. The retrieved electric field at the native AMPR resolution (thin solid line) generally agrees with LIP measurements (solid thick line) throughout the overflight. There are two peaks: one over the western feature at $200 \mathrm{~V} \mathrm{~m}^{-1}$ and another that reaches $300 \mathrm{~V} \mathrm{~m}^{-1}$ over the stronger eastern feature. The TMI-resolution retrieved electric fields, meanwhile, peak at $200 \mathrm{~V} \mathrm{~m}^{-1}$ in the center of the LIP feature. The coarse microwave grid prevents the retrieval from reproducing the dual-peak curve across the overflight, while higher brightness temperatures from beamfilling keep the retrieved electric fields from reaching the $300 \mathrm{~V} \mathrm{~m}^{-1}$ peak of the retrieval at the native AMPR resolution. Beamfilling is an important source of uncertainty for the satellite algorithm because of the comparably large pixel sizes of orbital instruments. Small isolated cases like the features in Fig. 1a can have peak electric fields and current densities that are underrepresented by the algorithm. For the case in Fig. 1, the peak electric field is underreported by $\sim 33 \%$ in the TMI-resolution retrieval.

The algorithm is constructed under the assumption of a convective charge structure that produces positive (upward) Wilson currents. This is consistent with the
AMPR $85 \mathrm{GHz} \mathrm{T}_{\mathrm{b}}$ - Native Resolution
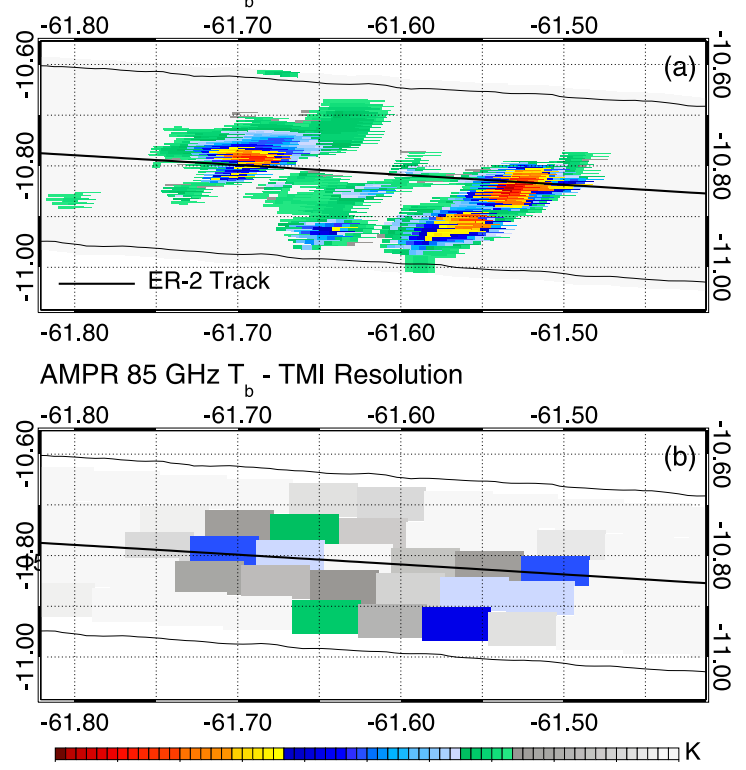

$\begin{array}{llllllllll}150 & 165 & 180 & 195 & 210 & 225 & 240 & 255 & 270 & 285 \\ \text { No Cloud }\end{array}$

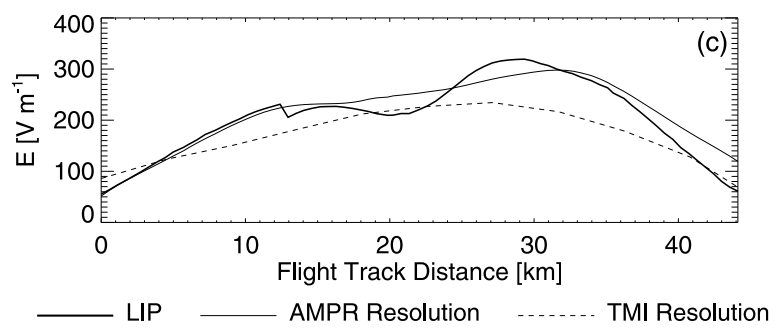

FIG. 1. An example AMPR overflight with LIP measurements and AMPR retrieved electric fields showing the $85-\mathrm{GHz}$ passive microwave brightness temperature field (a) on the native AMPR grid and (b) regridded to the resolution of the TMI, and (c) the strength of the measured and estimated electric field along the flight track.

ER-2 overflights, $93 \%$ of which recorded positive current (Mach et al. 2010). However, an anomalously high fraction of negative Wilson currents is found when only the ER-2 overflights of a mature system with large stratiform regions are considered (Deierling et al. 2014). Because the Peterson et al. (2015) algorithm has no mechanism for inferring the polarity of the storm, retrieved electric fields over stratiform regions may have the correct strength but the wrong sign. This can lead to total integrated Wilson currents in mesoscale convective systems (MCSs) that are notably stronger than what is considered a physical range.

We apply a simple convective and stratiform partitioning scheme to the AMPR data that assigns a cloud type based on the intensity and texture of the microwave signals in the $85-\mathrm{GHz}$ cloud scene. AMPR pixels that either have brightness temperatures below $200 \mathrm{~K}$ or are $20 \mathrm{~K}$ colder than the average brightness 

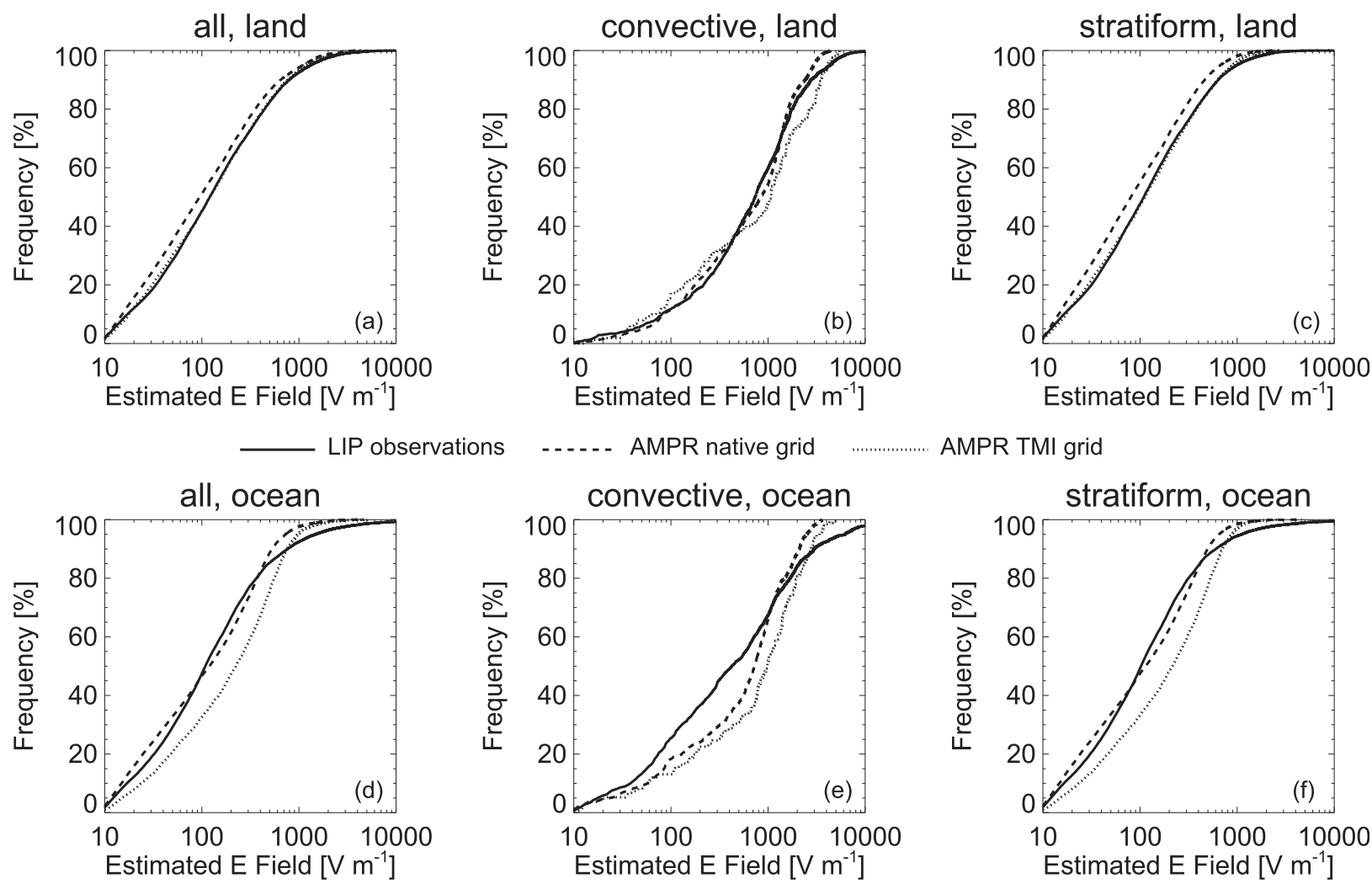

AMPR TMI grid

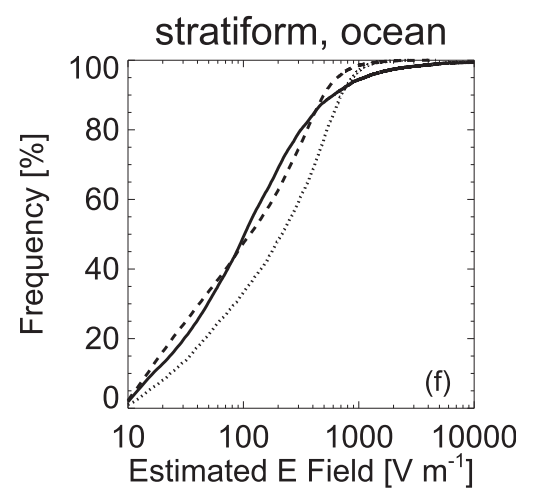

FIG. 2. ER-2 cumulative distribution functions (CDFs) of the strengths of observed LIP electric fields and passive microwave estimates at the native AMPR grid size and AMPR data regridded to the resolution of TMI.

temperature of the surrounding $>200-\mathrm{K}$ cloud feature are considered convective while the remaining cloud pixels are defined as stratiform.

Electric fields produced by the retrieval at the native AMPR resolution and the regridded TMI resolution in convective and stratiform clouds are compared in Fig. 2. Cumulative electric field distributions for all cloud types over land are shown in Fig. 2a. Overall, the range of electric fields provided by the retrieval agree with the LIP measurements. AMPR estimates at the native resolution (dashed line) fall slightly lower than LIP, but the TMI-resolution retrieved electric field distribution (dotted line) is nearly indistinguishable from the LIP curve (solid line). Beamfilling effects become apparent in the convection-only distributions (Fig. 2b). The retrieved electric fields at the native AMPR resolution agree with LIP in all but the most extreme cases, where the limited AMPR swath width often misses part of the storm, as noted in Peterson et al. (2015). By comparison, the TMI-resolution retrieval produces electric fields in the $200-500 \mathrm{~V} \mathrm{~m}^{-1}$ range less frequently than the native AMPR resolution retrieval.

Distributions of the retrieved electric fields over landbased stratiform clouds (Fig. 2c) are in better agreement with LIP than convection. This is partly due to the relatively large extent of stratiform regions compared to convective features and thus less beamfilling effects. What is important to note here is that the range of retrieved electric fields either agrees with LIP (TMI resolution) or slightly favors weaker retrieved values (AMPR resolution). The fact that stratiform retrieved electric fields are not significantly higher than LIP measurements suggests that the lack of polarity information is responsible for anomalously high stratiform currents and not-higher-than-expected electric fields produced by the retrieval.

Distributions for oceanic overflights are shown in Figs. 2d-f. The ocean surface filtering in Peterson et al. (2015) was ineffective to the point that the slope between $37-\mathrm{GHz}$ retrieved electric fields and LIP measurements was actually negative overall and the strongest retrieved electric fields were generally associated with clear-air cases. For this reason, we ignored the ocean results in Peterson et al. (2015) except in carefully selected cases where ocean surface artifacts were not evident.

With the new artifact removal scheme in this study, the $85-\mathrm{GHz}$ retrieved electric fields at least resemble the 
LIP measurements, but it is clear that ocean surface artifacts still remain. Such artifacts are particularly pronounced in the convective category and increase the retrieved electric fields in Fig. 2e to the point that $66 \%$ of the retrievals are greater than $400 \mathrm{~V} \mathrm{~m}^{-1}$ compared to $50 \%$ of the LIP measurements. Such a distinct separation between the curves in this region is not evident in land-based convection (Fig. 2b).

More recent field programs with ER-2 overflights, such as the Integrated Precipitation and Hydrology Experiment (IPHEx; Barros et al. 2014) in 2014 and the Geostationary Operational Environmental Satellite (GOES-R) field campaign in 2017 (Goodman et al. 2013), have reported AMPR polarization-corrected temperatures (PCTs; Spencer et al. 1989) that compensate for land and ocean emissivity differences and place passive microwave measurements in both regions on an even field. It was not possible to incorporate these measurements into the present study, but they will be considered in future work.

\section{c. Variations on the satellite passive microwave electric field retrieval algorithm}

We develop three variants of the algorithm outlined in section $2 b$ for use with satellite data that are designed to meet specific operational needs. These forks ingest similar passive microwave data but differ in the ancillary data that they require and in their computational expense. The motivations behind each fork and their deviations from the Peterson et al. (2015) algorithm are discussed below.

\section{1) THE PASSIVE MICROWAVE AND RADAR FORK}

The first fork of the satellite algorithm uses coincident radar measurements to construct an accurate representation of the three-dimensional precipitation structure of electrified clouds and is intended for general scientific use. It is computationally identical to the Peterson et al. (2015) algorithm, but it uses the coincident radar profiles to characterize the vertical extent of the electrified clouds rather than making assumptions based on a lookup table of average values. This allows the algorithm to represent the proximity of charges to the observer at $20-\mathrm{km}$ altitude in all types of electrified weather and to account for clouds that may have the same $85-\mathrm{GHz}$ brightness temperature but vastly different vertical extents, for example, land and ocean storms, or summer and winter convection. We use this version of the algorithm to compute the global generator current from TRMM and GPM observations, and to assess its temporal variability on many time scales in Peterson et al. (2017).
There are four caveats with this fork that limit its utility. First, the requirement of coincident radar profiles reduces the number of satellite platforms with which it can be used. Global coverage, for example, is practical only with the TRMM and GPM Core Observatory satellites, while regional analyses require data fusion with ground-based radar networks. Second, the added radar data increase the computational requirements of the algorithm in terms of data storage and CPU utilization. The pixel integration method used by this algorithm is computationally inefficient and adding the radar data further increases demand on the system. Third, radar profiles for the most intense convection may have $30-\mathrm{dB} Z$ echoes that encroach upon the $20-\mathrm{km}$ observer. Placing charges too close to the observer (i.e., at $19 \mathrm{~km}$ ) invalidates our charge layer simplification. The distancesquared term in Coulomb's law then produces unrealistic retrieved electric fields and Wilson currents for these cases. Such storms are rare but have a notable impact on the global retrieved current. We mitigate this effect by defining a maximum charge height at $18 \mathrm{~km}$.

Finally, the fourth limitation is the lack of polarity information provided by the algorithm. We combat this by looking only at convection and assuming a negligible overall net contribution from clouds identified as stratiform by the TRMM 2A23 algorithm (Awaka et al. 2007). Most electrified clouds (93\%) observed by the ER-2 have positive vertical electric fields resulting in upward-directed Wilson currents (Mach et al. 2010). Deierling et al. (2014) partitioned the ER-2 overflights by storm type and phase and found high fractions of downward currents with dissipating stage storms and stratiform clouds. Modeling results by Davydenko et al. (2011), meanwhile, found that whether an MCS contributes positive or negative current depends on its charge structure. Of the five "type A" charge structure MCSs sampled, all produced negative Wilson currents ranging from -3 to -9 A. An additional 10 "type B" MCSs were examined with some producing positive Wilson currents and others producing negative Wilson currents. Overall, more than $50 \%$ of stratiform clouds produced negative Wilson currents.

This is also supported by the analysis of positive and negative polarity lightning flashes recorded by the National Lightning Detection Network (NLDN) collocated with TRMM LIS and PR measurements in Peterson (2014). NLDN strokes in the southern portion of the United States within the TRMM PR swath are assigned to LIS flashes if they occur within the cloud region illuminated by the flash during the LIS flash duration. Illuminated cloud pixels are considered "convective" if they have a convective PR rain type and rainfall is detected by the PR near the surface, and 
"stratiform" if they have a stratiform PR rain type and near-surface rain. Of all NLDN strokes that occur within LIS flashes illuminating primarily $(>70 \%)$ stratiform cloud, $40 \%-60 \%$ were anomalous positive polarity. These results all suggest that we might expect a large fraction of the positive Wilson current contributed by electrified stratiform clouds to be nullified by invertedpolarity cases.

\section{2) THE PASSIVE-MICROWAVE-ONLY FORK}

The second fork is computationally identical to the Peterson et al. (2015) algorithm. Since it lacks vertical radar profiles, the passive-only fork is unable to represent the hydrometeor configurations in each cloud surveyed by the satellite, however. As in Peterson et al. (2015), this passive-only fork approximates the vertical extent of observed storms with average values from a TRMM-derived lookup table. The charge layer height will be assigned based on the geographical location of the storm and the local $85 \mathrm{GHz}$ PCT of the microwave pixel. Possible charge layer heights range from 8 to $14 \mathrm{~km}$. Because it does not depend on ancillary data, however, this fork can be used with any passive microwave radiometer in orbit that has an $85-\mathrm{GHz}$ channel.

In addition to the lack of measured cloud height information, the passive-only fork shares two of the limitations of the first radar-added fork: the computational expense of integrating over satellite swaths and the lack of polarity information that motivates us to focus on convective precipitation.

\section{3) THE MICROWAVE COLD CLOUD FEATURE FORK}

While the first two forks have a research focus and provide the most accurate current estimates possible for a given storm, the third fork prioritizes computational efficiency in order to minimize product latency. Rather than integrating pixel by pixel over hundreds to hundreds of thousands of orbital swaths, the third fork queries a database of passive microwave cold cloud features $(<250 \mathrm{~K}$ at $85 \mathrm{GHz})$ and uses the reported feature areal extents and minimum brightness temperatures to infer the amount of current the feature should produce. Because it relies on the least detailed representation of the distribution of charge across the electrified cloud, it is intended for near-real-time applications as a "first guess" to be replaced by the passiveonly or radar-added retrieved currents once they finish processing. It can also be used to quantify global changes in the overall frequency, intensity, and scale of electrified weather on long time scales.

The feature-level fork is constructed from AMPR $85 \mathrm{GHz}<250 \mathrm{~K}$ features. Total Wilson currents are computed by integrating the Peterson et al. (2015) pixel-level current densities over the feature area. These pixel-integrated currents are then compared with a feature-level proxy that depends on extent and convective intensity. The feature-level current proxy is defined as follows:

$$
\begin{aligned}
I_{\mathrm{fea}}= & a_{1}\left(c_{1} A_{\mathrm{Tb}<250 \mathrm{~K}}+c_{2} A_{\mathrm{Tb}<200 \mathrm{~K}}+c_{3} A_{\mathrm{Tb}<150 \mathrm{~K}}\right) \\
& \times\left(300-T_{\mathrm{b}-\min }\right)^{n}+a_{2},
\end{aligned}
$$

where $T_{\mathrm{b}-\min }$ is the minimum $85-\mathrm{GHz}$ brightness temperature of the feature; $A_{\mathrm{Tb}<250 \mathrm{~K}}, A_{\mathrm{Tb}<200 \mathrm{~K}}$, and $A_{\mathrm{Tb}<150 \mathrm{~K}}$ are the feature areas with brightness temperatures below 250,200 , and $150 \mathrm{~K}$, respectively; and $a_{1}, a_{2}$, $c_{1}, c_{2}, c_{3}$, and $n$ are constants that we tune to find the best fit with the total integrated current provided by the Peterson et al. (2015) algorithm.

We find an optimal fit for the pixel-integrated current with coefficients of $n=2, a_{1}=1.12 \times 10^{-8} \mathrm{~A} \mathrm{~m}^{-2} \mathrm{~K}^{-2}$, $a_{2}=0, c_{1}=c_{2}=1$, and $c_{3}=3$. Feature-level currents are compared with pixel-integrated AMPR currents $\left(r^{2}=\right.$ $0.98)$ and LIP-only estimates $\left(r^{2}=0.75\right)$ in Fig. 3. The LIP current estimates are provided by Mach et al. (2010) and collocated to the nearest AMPR feature. Methodological differences limit the goodness of fit with the LIP currents (Fig. 3b), but the two AMPR estimates agree across the ER-2 current spectrum. Current distributions are shown for the three estimation methods in Fig. $3 \mathrm{~b}$. All three distributions peak between 100 and $200 \mathrm{~mA}$. The key difference between the Peterson et al. (2015) integrated currents and the feature-level currents is that the latter is more likely to miss weak events. Features with no discernible feature-level current account for $22 \%$ of all AMPR features compared to $2 \%$ for passiveonly AMPR pixel-integrated currents. However, these weaker features that produce $<0.1 \mathrm{~A}$ are primarily weakly electrified shower clouds that are not evident in the LIP Wilson current estimates, either.

\section{Results}

We compare the different satellite estimates to one another and to known measures of atmospheric electricity in the following sections. Retrieved currents are compared between the forks in section 3a. Retrieved currents are then compared to LIS total lightning activity in section $3 b$. Finally, the diurnal cycles for the total retrieved current are compared with the Carnegie curve in section $3 \mathrm{c}$.

\section{a. Statistics of satellite-retrieved Wilson current}

The key computational difference between the three forks lies in how much information each has about the three-dimensional structure of the electrified clouds. 

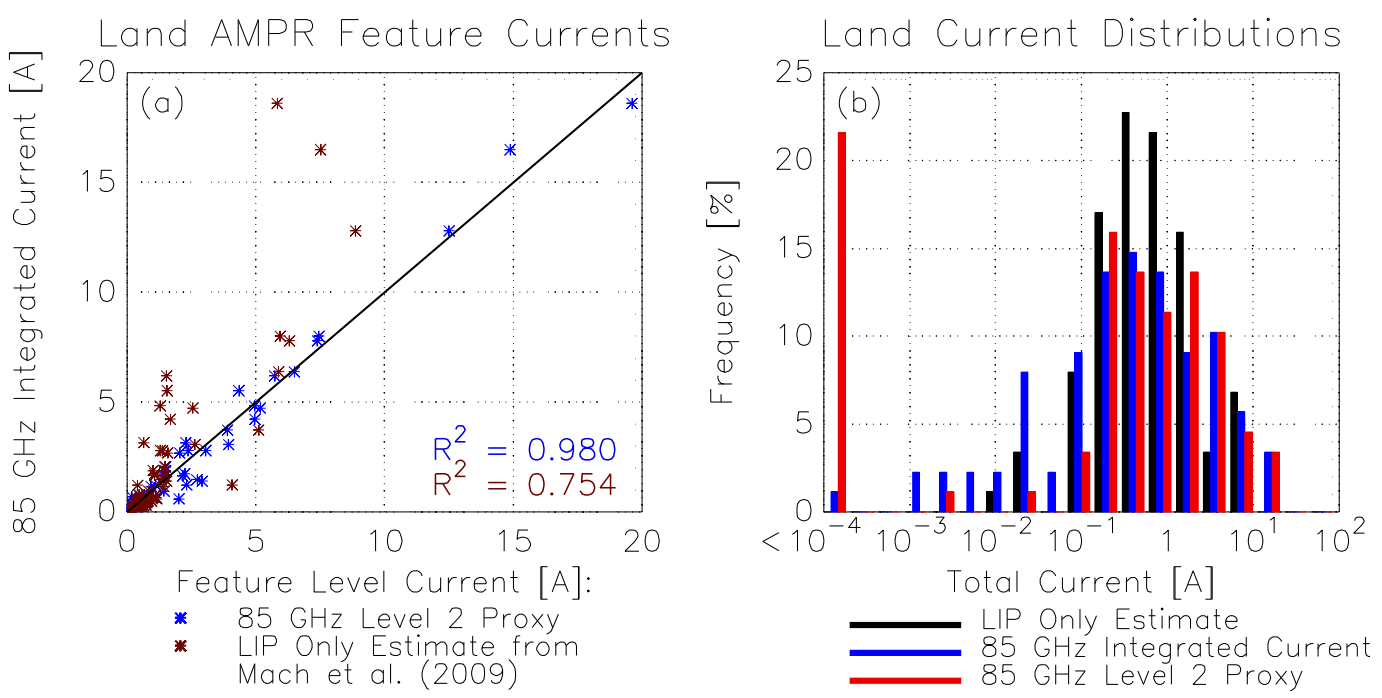

FIG. 3. ER-2 estimated Wilson current strengths from AMPR and LIP for the same overflights. (a) Pixelintegrated retrieved currents are compared to a feature-level proxy current estimate and the LIP-only estimate from Mach et al. (2009). (b) Histograms of AMPR and LIP estimated currents.

The radar-added fork has the most detailed representation of the horizontal and vertical extents of the cloud. The passive-only fork has the same picture of the electrified cloud horizontal extent with additional ambiguity in the vertical extent as a result of the use of a lookup table. The feature-level fork has an unclear picture of the horizontal and vertical geometry of the cloud. It is informed that there is an electrified cloud at a geographical location and is provided information on its spatial extent and peak intensity, but it has no information on how charge is distributed over the feature area. It attempts to infer the Wilson current using only these feature-level properties.

The result of these algorithm differences can be seen in the global distributions of total current. Figure 4 shows the global (Fig. 4a), zonal (Fig. 4b), and meridional (Fig. 4c) distributions of current retrieved by the radar-added algorithm using the first 2 years of GPM Core Observatory data. The global generator current is concentrated in the tropics (Fig. 4b) with separate peaks above and below the equator. Secondary maxima can be noted in the midlatitudes at $\sim 30^{\circ}$ north or south before falling off to zero in the high latitudes. The current is not distributed evenly along the equator, but it is instead clustered into three key regions known as the continental chimneys of the Americas, Africa and Europe, and Asia (Fig. 4c).

To contrast the global current from the radar-added fork in Fig. 4, the global current estimated using the feature-level fork applied to 25 years of SSM/I data is shown in Fig. 5. The zonal and meridional total current distributions from GPM are displayed as dashed lines for reference. The same features from Fig. 4 can be identified in Fig. 5, including a concentration of current along the equator and in the three continental chimney regions. Unlike the pixel-integrated retrieved currents in Fig. 4, however, the feature-level fork produces significant current contributions in the northern expanses of Europe and North America. Additionally, the Africa chimney produces almost as much current as the Americas rather than coming in a distant third as before. Thus, while the broad strokes of the current map remain the same, differences in how the forks describe storm structure affect the fraction of the total current contributed by a given region of the world.

Differences between the algorithm variants can also be noted in the distributions of current from individual satellite PFs (Liu et al. 2008). We define electrified cloud features (ECFs) as contiguous regions of rainfall near the surface measured by the TRMM PR (radar precipitation features) that are at least four PR pixels in size and produce Wilson current according to the retrieval. Histograms and cumulative distributions for land and ocean thunderstorms and shower cloud ECFs are shown in Fig. 6. An ECF is identified as a thunderstorm if the LIS detected a lightning flash within its boundaries. Land is partitioned from the coastal ocean at the shoreline, while the open ocean is distinguished from the coastal ocean at a constant $1000 \mathrm{~km}$ from shore.

Generally speaking, the total Wilson currents supplied by electrified shower clouds can be described in terms of milliamps, while thunderstorms typically 


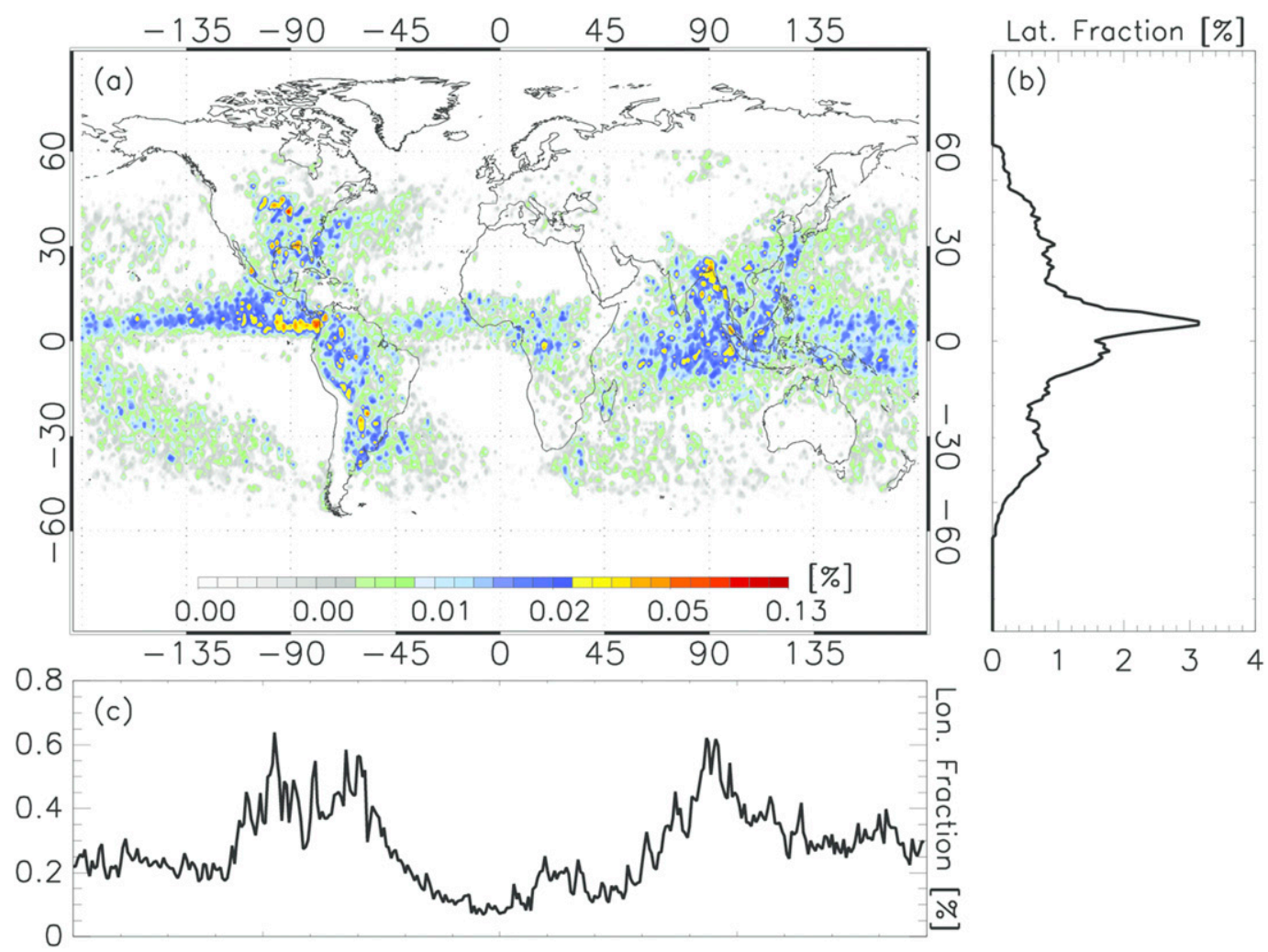

FIG. 4. The global average distribution of Wilson current retrieved from GPM passive microwave and precipitation radar observations. (a) The map of mean current, (b) zonal current distribution, and (c) meridional current distribution are shown as a fraction of the total.

produce currents in the range of amps. The shower cloud Wilson currents retrieved using either the radar-added or passive-only algorithm converge after $100 \mathrm{~mA}$, but the passive-only algorithm is more likely to produce weaker currents $(<1 \mathrm{~mA})$ than the radaradded algorithm. The feature-level fork, in contrast, produces shower cloud currents in excess of $100 \mathrm{~mA}$ more frequently than either of the pixel-integrated forks. Though the peaks of the feature-level and radar-added histograms overlap, the propensity of the feature-level algorithm to produce strong ESC currents and its inability to resolve currents below the milliamp range leads to a cumulative ESC distribution that is higher than the other forks-especially over the ocean (Figs. 6c,e).

The feature-level retrieval that frequently produced strong ESC currents also produces the weakest thunderstorm currents. The feature-level thunderstorm current histogram eventually agrees with the passive-only curve, but only for the strongest land and ocean thunderstorms. The median thunderstorm Wilson current from the feature-level algorithm is $0.04 \mathrm{~A}$ over land, $0.09 \mathrm{~A}$ over the coastal ocean, and $0.1 \mathrm{~A}$ over the open ocean compared to $0.15,0.3$, and $0.5 \mathrm{~A}$ for the passive-only fork, and $0.3,0.7$, and $1 \mathrm{~A}$ for the radar-added fork. The radaradded algorithm routinely produces stronger thunderstorm currents than the passive-only fork because the radar profiles account for high echo tops in individual cases of intense convection. The lookup table used in the passive-only fork provides only an average height across many storms.

\section{b. Retrieved Wilson currents and LIS total lightning}

The combination of passive microwave observations and total lightning detection on the TRMM satellite makes it an ideal platform to examine the link between lightning production and the microphysical properties of the parent thunderstorm. We are particularly interested in how steady-state Wilson currents $(\sim 1 \mathrm{~A} ;>\sim 600 \mathrm{~s})$ that drive the direct current $(\mathrm{dc})$ branch of the global circuit relate to the rapid high-current lightning discharges $(\sim 1000 \mathrm{~A} ;<1 \mathrm{~s})$ that drive the alternating current (ac) branch of the GEC (Rycroft et al. 2008). As both processes stem from the same separation of charged ice particles in an electrified cloud, there is likely some connection between them. 


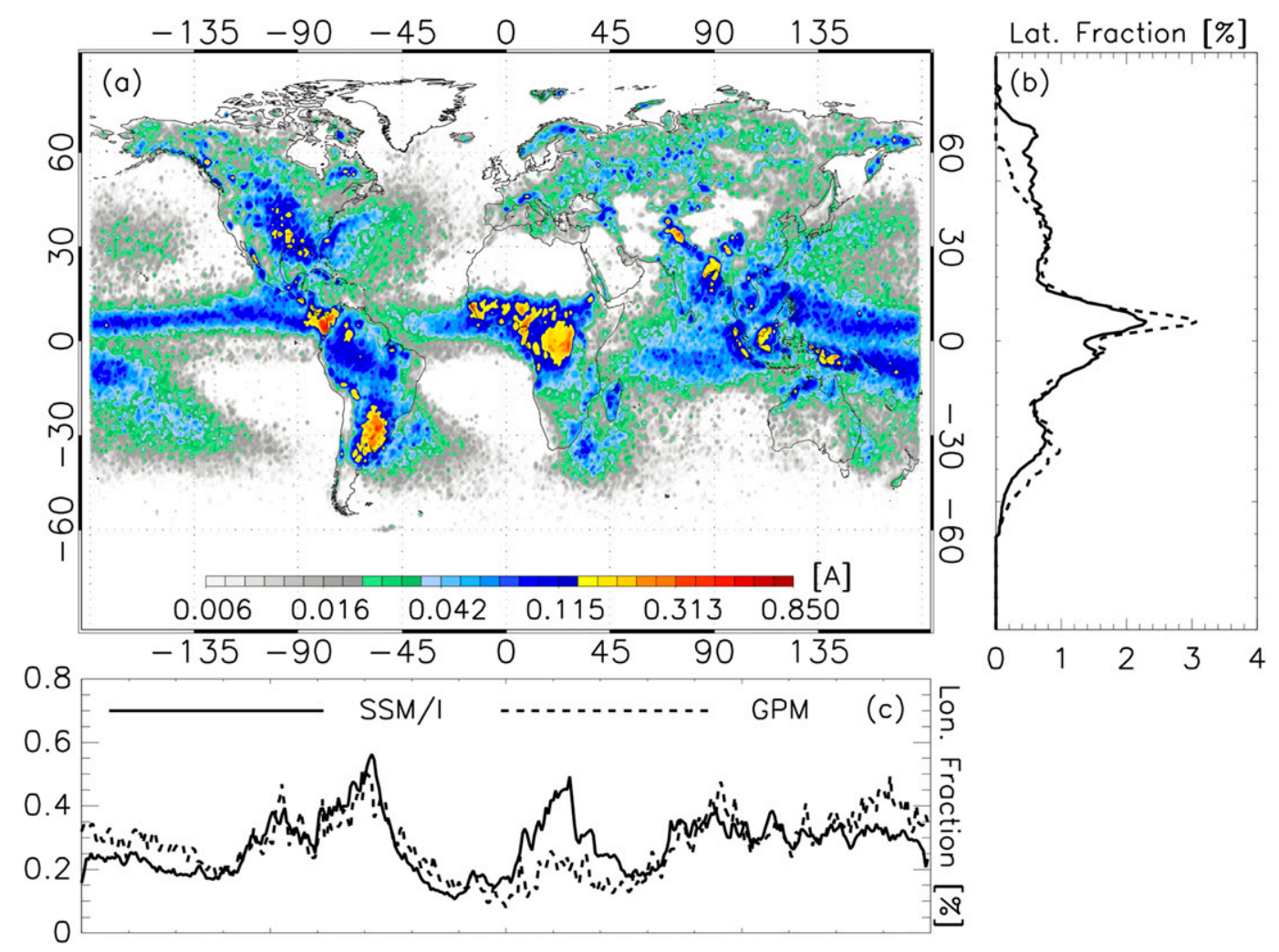

FIG. 5. As in Fig. 4, but using SSM/I passive microwave observations only to construct the global current distributions. GPM distributions are overlaid in (b) and (c).

The first question that we address is how much current is produced by a storm before it begins to pose a lightning threat. Figure 7 computes the fraction of features with a particular current that are thunderstorms in land, coastal, and open ocean regions. Thunderstorm probabilities are computed separately for each fork of the satellite algorithm applied to the same set of TRMM ECFs. In each case, the probability of lightning increases with Wilson current on a broad range from $10^{-5}$ to $10 \mathrm{~A}$. The radar-added and passive-only forks approach $100 \%$ beyond $10 \mathrm{~A}$.

We will focus on the radar-added fork because it has the best representation of the three-dimensional structure of the storm. If we consider a $1 \%$ chance of lightning to be a reasonable level of risk, then we should pay attention to land-based storms that produce $>1.7 \mathrm{~mA}$, coastal oceanic storms that produce $>27 \mathrm{~mA}$, and open ocean storms that produce $>100 \mathrm{~mA}$. These thresholds also include $80 \%$ of ESCs over land, $15 \%$ of ESCs over the coastal ocean, and 5\% of ESCs over the open ocean as false detections (Figs. 6a-c). Increasing the acceptable risk to $5 \%$ results in a lightning threshold of 12,80 , and $400 \mathrm{~mA}$ for land, coastal ocean, and open ocean regions, respectively, while increasing the acceptable risk further to $10 \%$ places the lightning threshold at 27,180 , and $960 \mathrm{~mA}$, respectively. Meanwhile, $75 \%$ of land-based storms that produce $1 \mathrm{~A}$ of current are thunderstorms compared to just $36 \%$ of coastal ocean storms and $12 \%$ of open ocean storms.

ECF retrieved Wilson currents produced by the three forks are compared with LIS flash rates in Fig. 8. Twodimensional cumulative histograms are shown. The first, second (median), and third quartiles of the current distribution for a given flash rate are overlaid. A statistical fit to the median is also shown to highlight the difference in slope between the distributions. The histograms for each fork follow a power-law relationship that varies considerably between land and ocean regions. A typical land-based thunderstorm that is producing one flash per minute tends to generate tens of milliamps. Its coastal counterparts, however, are likely to produce $>100 \mathrm{~mA}$, while thunderstorms with the same flash rate over the open ocean often produce hundreds of milliamps or more of Wilson current.

While the one-flash-per-minute intercept increases offshore, the slopes of the distributions decrease. The retrievals suggest that high-flash-rate storms-with 100 or more flashes per minute-produce the same amount of current whether they occur in continental 

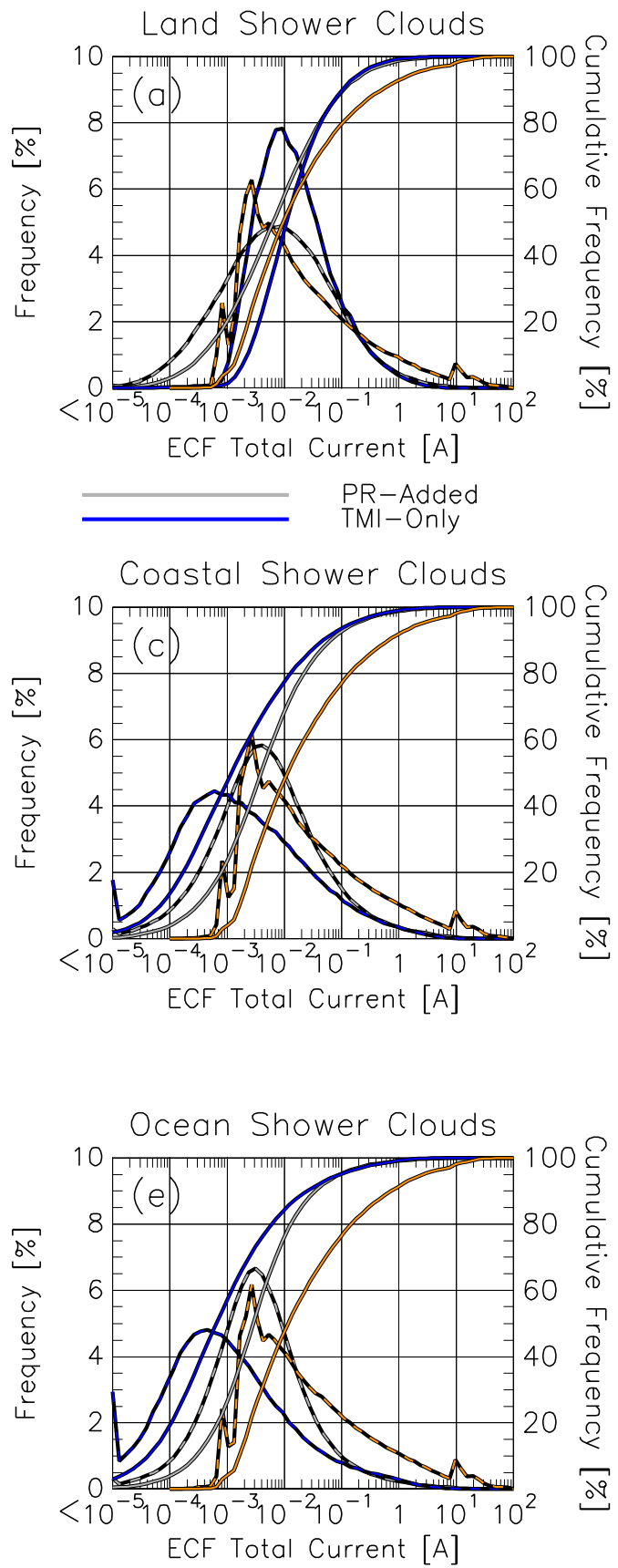

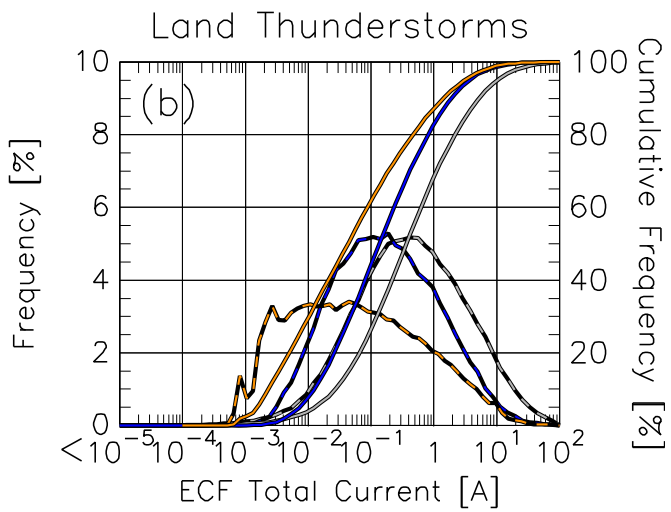

Feature Approximate

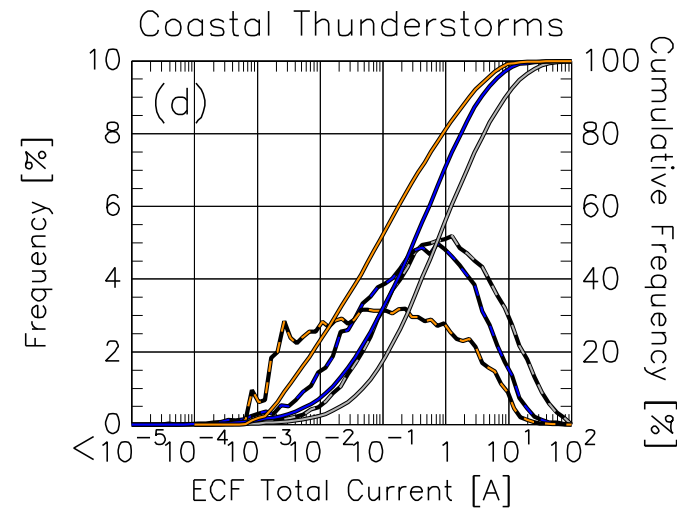

FIG. 6. Histograms and cumulative distributions of the Wilson current retrieved using the radar-added algorithm with TMI and PR observations (gray), the passive-only algorithm using TMI observations (blue), and feature-level algorithm (yellow). Separate distributions are shown for (a),(c),(e) ESCs and (b),(d),(f) thunderstorms and for (a),(b) land-based, (c),(d) coastal ocean, and (e),(f) open ocean storms.

or oceanic regions. Another way of interpreting this trend is that while lightning may not be triggered until storms produce considerably stronger Wilson currents in an oceanic environment, the increase in current that accompanies each additional flash per minute is lower over the ocean than over land.

\section{c. Retrieved Wilson currents and the Carnegie curve}

The Carnegie curve tracks the diurnal change in the GEC through the fair-weather load on the circuit. It is a robust climatological variation that has been documented for nearly a century (Whipple 1929; Whipple and Scrase 1936). The Carnegie curve is the best 

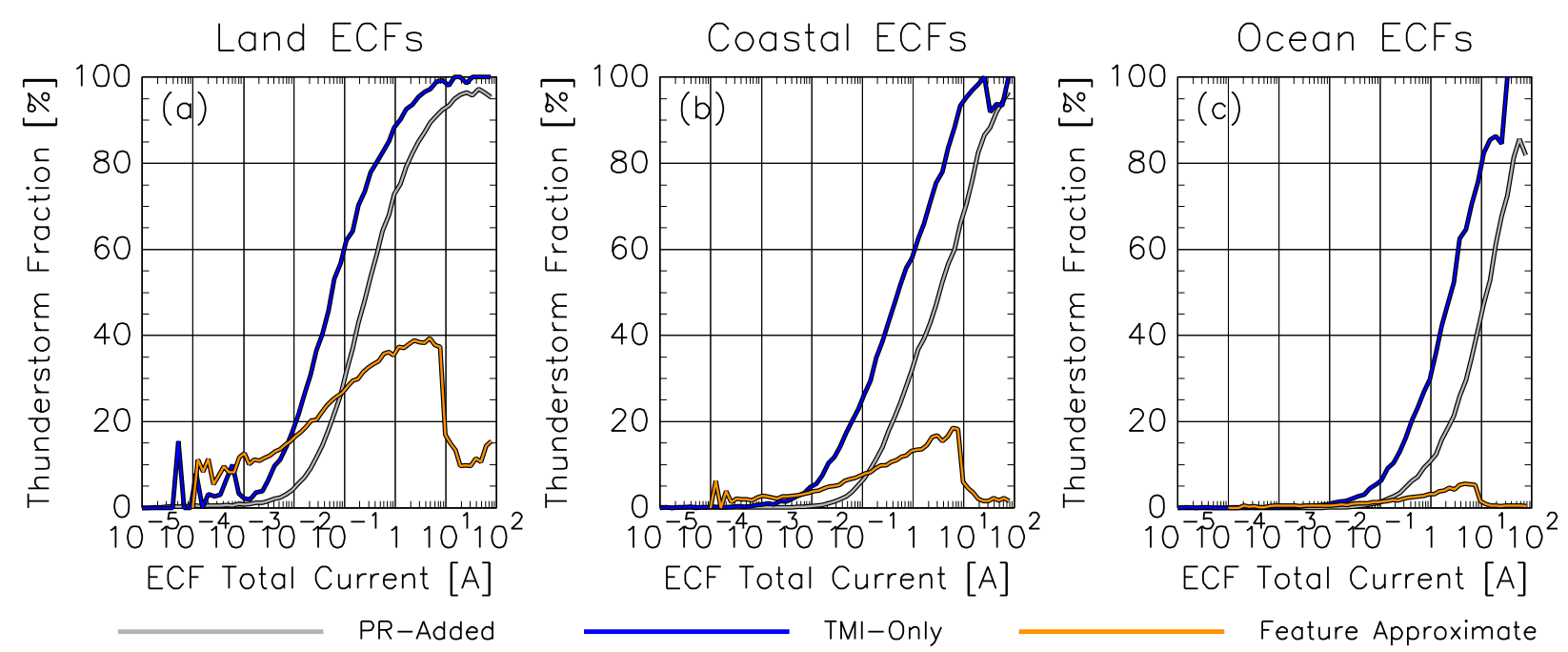

FIG. 7. The fraction of features with a given total current that are thunderstorms for (a) land, (b) coastal ocean, and (c) open ocean features. Separate curves are shown for the radar-added algorithm with TMI and PR (gray), the passive-only algorithm with TMI (blue), and the feature-level algorithm (yellow).

available diagnostic for the performance of the satellite retrieval because it integrates total Wilson current contributions from across the globe. If the Wilson currents produced by the algorithm are reasonable for individual ECFs, then integrating them over 13 years of TRMM observations should produce a good agreement with the Carnegie curve.

Figure 9 computes the diurnal cycle of the total generator current across the TRMM domain retrieved using the radar-added fork (Fig. 9a), the passive-only fork (Fig. 9b), and the feature-level fork (Fig. 9c). The overall total current (gray dashed) and land-only total current (blue dashed) are compared with the classic annualaveraged Carnegie curve (gray) and the LIS/OTD lightning climatology (blue). The globe is divided into longitude quadrants aligned with the continental chimneys. Current contributions from the Americas $\left(124.5^{\circ}-34.5^{\circ} \mathrm{W}\right)$, Africa and Europe $\left(34.5^{\circ} \mathrm{W}-55.5^{\circ} \mathrm{E}\right)$, Asia $\left(55.5^{\circ}-145.5^{\circ} \mathrm{E}\right)$, and the Pacific $\left(145.5^{\circ} \mathrm{E}-124.5^{\circ} \mathrm{W}\right)$ are shown as thin solid lines.

The diurnal cycles produced by the radar-added fork are shown in Fig. 9a. The retrieved global current agrees in both phase and amplitude with the Carnegie curve, while the total land-only current agrees in overall phase and amplitude with the diurnal cycle of lightning, which primarily occurs over land. The key difference between the retrieved current curve and the Carnegie curve is that the retrieval produces more current between 0500 and 1200 UTC and less current between 1200 and 1800 UTC than the Carnegie curve would suggest. Peterson et al. (2017) links this discrepancy to the simplification of the electrified cloud charge structure to a single layer of net charges. If the radar profiles place charges too close to the observer, then the distancesquared term in Coulomb's law generates unrealistic electric fields. This was remedied using an observer at a higher altitude that was not too close to the cloud top and that produced an excellent agreement with modern observations of the Carnegie curve (Burns et al. 2017) in all seasons.

The passive-only retrieval is identical to the radaradded retrieval in all aspects other than how it handles the vertical extent of electrified clouds. It produces an improved fit with the Carnegie curve even without the added radar profile information in Fig. 6b. The chimney contributions (solid thin lines) are nearly identical between Figs. $6 \mathrm{a}$ and $6 \mathrm{~b}$ with two key exceptions: the Africa peak at 1500 UTC accounts for a larger share of the total current in the passive-only fork, while the current contributed by nocturnal storms over Asia at 2000 UTC rivals the collocated Americas' peak in the radar-added fork only.

Unlike the first two forks that use a pixel-integration technique, the feature-level retrieval underestimates the amplitude of the Carnegie curve and peaks too early in the afternoon. This is largely due to overestimating the oceanic contribution to the total, as the land-based curve (dot-dashed line) peaks at the same time as the Carnegie curve. Much of the bias comes from the Pacific quadrant, which contributes more than Africa and almost as much as the Americas and Asia at all UTC hours. Improving the representation of oceanic and possibly stratiform contributions to the feature-level retrieval will be necessary for it to be used beyond a first-guess estimate. 

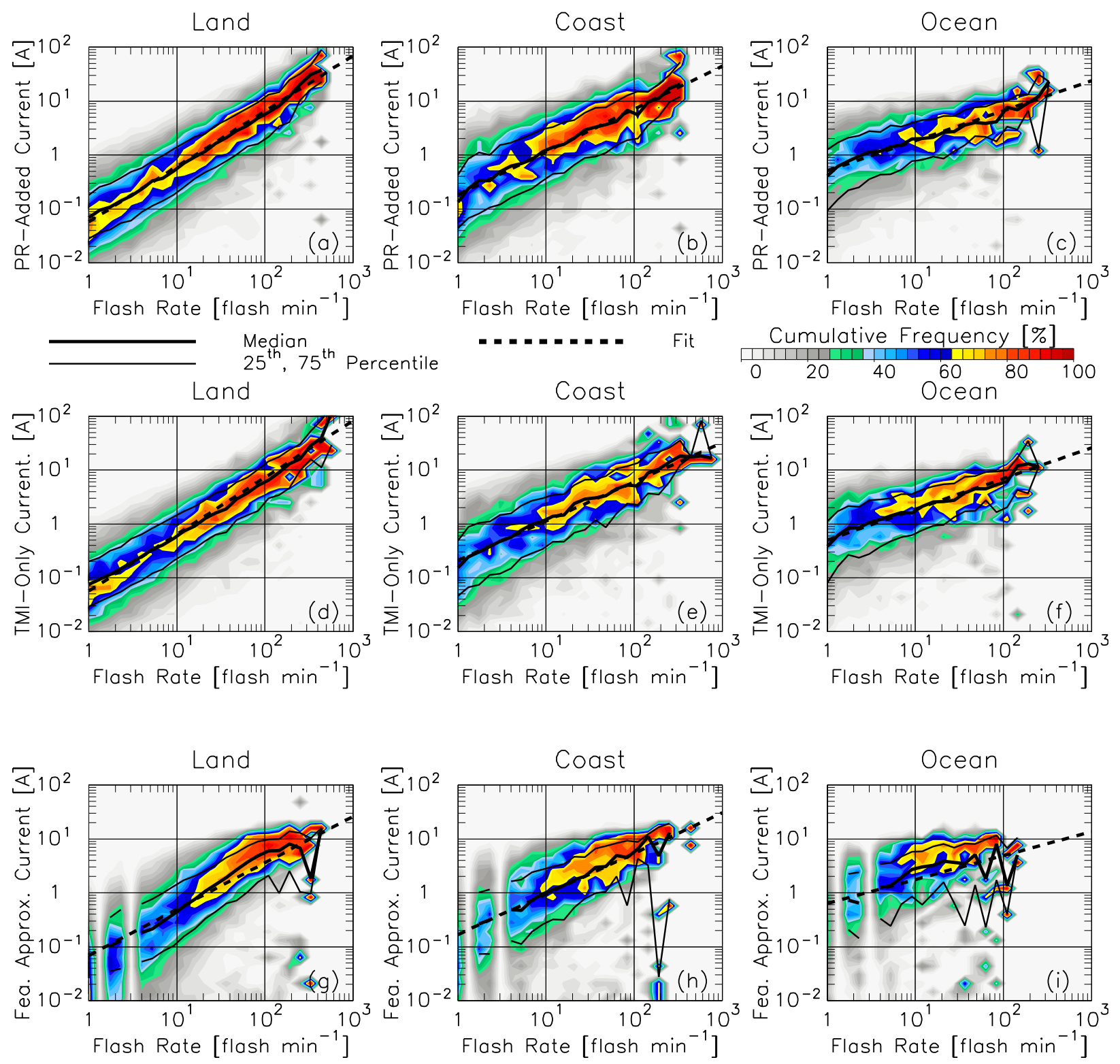

FIG. 8. Cumulative two-dimensional distributions of LIS total flash rate and the total Wilson current retrieved by the radar-added algorithm with (a)-(c) TMI and PR, (d)-(f) the passive-only algorithm with TMI, and (g)-(i) the feature-level algorithm. Separate distributions are shown for (left) land-based, (middle) coastal ocean, and (right) open ocean thunderstorms. Quartiles for the distribution of current at a given flash rate and a statistical fit to the median current are overlaid.

The degree to which each retrieval agrees with the Carnegie curve is quantified in Table 1. Root-mean-square (RMS) and maximum difference error statistics are reported for the diurnal cycles of the total current retrieved by each fork over the entire TRMM domain and over land only. Error statistics were reported in Peterson et al. (2017) that summarized previous approximations in the literature. The two closest approximations to the Carnegie curve came from Mach et al. (2011) and Liu et al. (2010). Mach et al. (2011) modified the diurnal cycle in total lightning activity to account for Wilson current contributions from ESCs, resulting in a 4.4\% RMS difference and an $11 \%$ maximum difference. These results depend on ER-2 sampling biases of thunderstorms relative to ESCs, however. Assuming that the ER-2 undersamples ESCs by a factor of 3 improves the agreement with the Carnegie curve to $3.4 \%$ RMS error and a $6.9 \%$ maximum difference.

Liu et al. (2010), meanwhile, approximates the Carnegie curve using thunderstorm and ESC rainfall contributions 

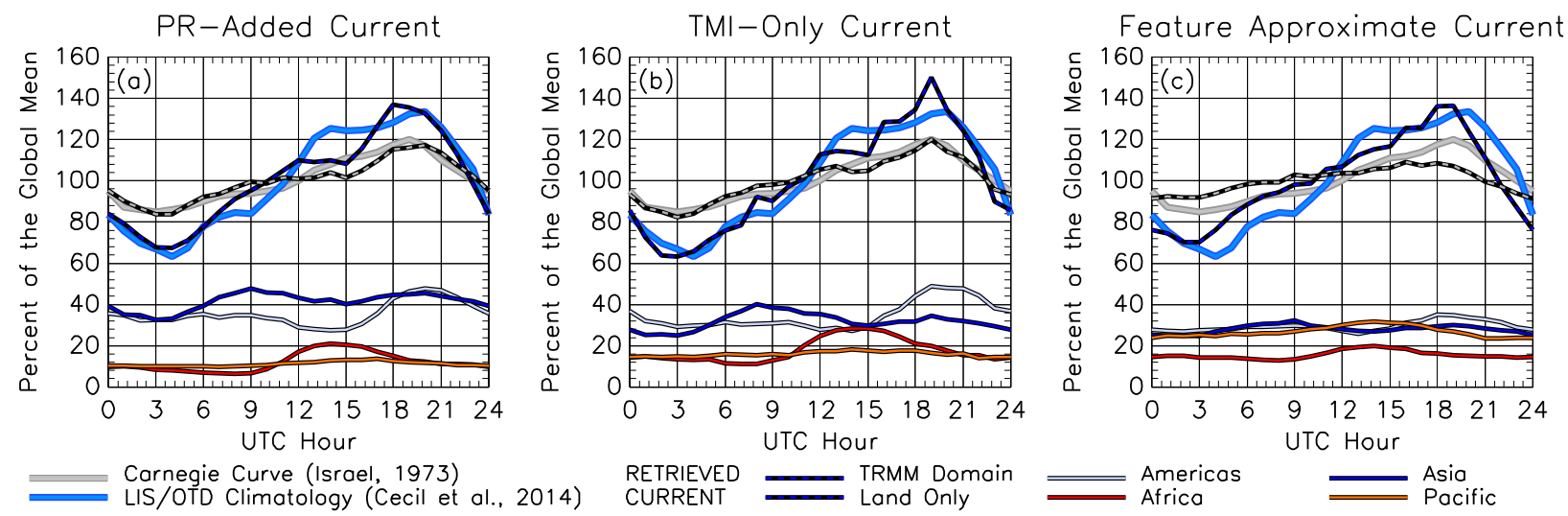

FIG. 9. Diurnal cycles of the retrieved current across the TRMM domain calculated using the radar-added algorithm with (a) TMI and PR data, (b) the passive-only algorithm with TMI, and (c) the feature-level algorithm. The total current (gray dashed) is compared with the land-only current (blue dashed) and both the Carnegie curve (gray solid) and the LIS/OTD climatology from Cecil et al. (2014) (blue solid). The current contributions from longitude quadrants centered on the tropical chimneys are also shown (thin solid).

as a proxy for Wilson current. The diurnal cycle of rainfall from all regions and storm types produces a curve with a $4.1 \%$ RMS difference and a $9 \%$ maximum difference from the Carnegie curve. If only land-based thunderstorms are considered, however, then the fit improves to $3.3 \%$ RMS error and a $6.4 \%$ maximum difference.

The radar-added fork applied to the TRMM dataset approximates the Carnegie curve with a $3.8 \%$ RMS error and a $9.6 \%$ maximum difference. Unlike Liu et al. (2010), looking at land only worsens our error statistics to $11.2 \%$ RMS error and a $20 \%$ maximum difference. Thus, land and ocean currents are necessary for the retrieval to capture the Carnegie curve. The passiveonly fork, meanwhile, reproduces the Carnegie curve to within $3.2 \%$ RMS error and with a $6.1 \%$ maximum difference. These statistics are notably better than the optimal Carnegie curve matches in Liu et al. (2010) and Mach et al. (2011), but without the tuning they employ to achieve an excellent fit.

Finally, the feature-level fork produces the worst error statistics with $7.3 \%$ RMS error and a $12.9 \%$ maximum difference. Thus, the feature-level approximation is best suited as an interim product that can map and monitor global thunderstorms and ESCs while the other forks are still processing.

\section{Conclusions}

The Peterson et al. (2015) electric field retrieval algorithm is adapted for use with passive microwave satellite datasets. Three variants, or "forks," are defined that balance the availability of coincident ancillary data with computational efficiency and product latency. These forks primarily differ in how they represent the three-dimensional distribution of charge in electrified clouds. The first fork emulates the original Peterson et al. (2015) algorithm while requiring coincident radar profiles to directly prescribe the vertical extent of the electrified cloud. The second fork is a direct application of the Peterson et al. (2015) and uses a lookup table to infer the vertical cloud extent. Finally, the third fork estimates Wilson currents from the properties of passive microwave cold cloud features. The feature-level fork requires the least amount of input data and is devised to provide a "first guess" approximation of the Wilson current from an observed electrified cloud feature.

We apply these algorithms to SSM/I, TRMM, and GPM Core Observatory measurements to compare the retrieved current from individual storms, global maps of the retrieved current, and the diurnal cycle of the global retrieved current. We also compare the retrieved currents to LIS total lightning measurements and the Carnegie curve. Familiar elements of global atmospheric electricity, such as high contributions from the tropical chimneys

TABLE 1. RMS and maximum differences from the Carnegie curve for the total current retrieved by the radar-added, passive only, and feature-level forks applied to TRMM observations.

\begin{tabular}{lcc}
\hline \hline & $\begin{array}{c}\text { RMS diff from } \\
\text { Carnegie (\%) }\end{array}$ & $\begin{array}{c}\text { Max diff from } \\
\text { Carnegie (\%) }\end{array}$ \\
\hline Radar-added retrieval & & \\
$\quad$ Entire TRMM domain & 3.8 & 9.6 \\
$\quad$ Land only & 11.2 & 19.5 \\
Passive-only retrieval & & \\
$\quad$ Entire TRMM domain & 3.2 & 6.1 \\
$\quad$ Land only & 14.5 & 30.3 \\
Feature-level approximation & & \\
$\quad$ Entire TRMM domain & 7.3 & 12.9 \\
$\quad$ Land only & 10.4 & 18.9 \\
\hline
\end{tabular}


and the distinct diurnal cycle of the Carnegie curve, are found in the satellite-retrieved currents. The retrieval likewise reinforces findings from the ER-2 aircraft data that oceanic thunderstorms produce more Wilson current than their land-based counterparts.

We plan to use these algorithms in a variety of applications that describe the global state of electrified weather. Long-term passive microwave records provided by instruments such as SSM/I will allow us to document the variability of the global generator current over multiple decades. Intercalibrated passive microwave measurements by the radiometers of the GPM constellation can be used to construct global current maps every $\sim 3 \mathrm{~h}$ and to describe changes in the supply side of the GEC from one day to the next. These retrieved currents will also allow us to make direct comparisons between the GEC generator current provided by electrified weather and ground-based fair-weather electric field and global temperature measurements.

Acknowledgments. This work was partly funded by the National Science Foundation Frontiers in Earth System Dynamics Grant AGS-1135446 and NSF Grant 1519006. The National Center for Atmospheric Research is sponsored by the National Science Foundation.

\section{REFERENCES}

Adlerman E. J., and E. R. Williams, 1996: Seasonal variation of the global electric circuit. J. Geophys. Res., 101, 29 679-29 688, https://doi.org/10.1029/96JD01547.

Awaka, J., T. Iguchi, and K. Okamoto, 2007: Rain type classification algorithm. Measuring Precipitation from Space: EURAINSAT and the Future, V. Levizzani, P. Bauer, and F. J. Turk, Eds., Advances in Global Change Research, Vol. 28, Springer, 213-224, https://doi.org/10.1007/978-1-40205835-6_17.

Bailey, J. C., R. J. Blakeslee, D. E. Buechler, and H. J. Christian, 2007: Diurnal lightning distributions as observed by the Optical Transient Detector (OTD) and the Lightning Imaging Sensor (LIS). Proc. 13th Int. Conf. on Atmospheric Electricity, Beijing, China, International Commission on Atmospheric Electricity, 4 pp., https://ntrs.nasa.gov/search.jsp?R=20070038367.

Barros, A. P., and Coauthors, 2014: IPHEx 2014: Observations of orographic precipitation processes in the Southern Appalachians. 2014 Fall Meeting, San Francisco, CA, Amer. Geophys. Union, Abstract H23P-01.

Bateman, M. G., M. F. Stewart, R. J. Blakeslee, S. J. Podgorny, H. J. Christian, D. M. Mach, J. C. Bailey, and D. Daskar, 2007: A low-noise, microprocessor-controlled, internally digitizing rotating-vane electric field mill for airborne platforms. J. Atmos. Oceanic Technol., 24, 1245-1255, https://doi.org/ 10.1175/JTECH2039.1.

Blakeslee, R. J., and Coauthors, 1999: Diurnal lightning distribution as observed by the Optical Transient Detector (OTD). 11th International Conference on Atmospheric Electricity, H. J. Christian, Ed., NASA Conf. Publ. NASA/CP-1999209261, 742-745.
Blyth, A. M, H. J Christian Jr., K. Driscoll, A. M Gadian, and J. Latham, 2001: Determination of ice precipitation rates and thunderstorm anvil ice contents from satellite observations of lightning. Atmos. Res., 59-60, 217-229, https://doi.org/10.1016/ S0169-8095(01)00117-X.

Brooks, C. E. P., 1925: The distribution of thunderstorms over the globe. Geophys. Mem., 3 (24), 147-164.

Burns, G. B., A. V. Frank-Kamenetsky, B. A. Tinsley, W. J. R. French, P. Grigioni, D. Camporeale, and E. A. Bering, 2017: Atmospheric global circuit variations from Vostok and Concordia electric field measurements. J. Atmos. Sci., 74, 783-800, https:// doi.org/10.1175/JAS-D-16-0159.1.

Cecil, D. J., S. J. Goodman, D. J. Boccippio, E. J. Zipser, and S. W. Nesbitt, 2005: Three years of TRMM precipitation features. Part I: Radar, radiometric, and lightning characteristics. Mon. Wea. Rev., 133, 543-566, https://doi.org/10.1175/ MWR-2876.1.

, D. E. Buechler, and R. J. Blakeslee, 2014: Gridded lightning climatology from TRMM-LIS and OTD: Dataset description. Atmos. Res., 135-136, 404-414, https://doi.org/ 10.1016/j.atmosres.2012.06.028.

Davydenko, S. S., T. C. Marshall, and M. Stolzenburg, 2011: Modeling the electric properties of MCS stratiform regions and their contribution to the global circuit. Proc. XIV Int. Conf. on Atmospheric Electricity, Rio de Janeiro, Brazil, International Commission on Atmospheric Electricity, 7-12.

Deierling, W., C. Kalb, D. Mach, C. Liu, M. Peterson, and R. Blakeslee, 2014: On the variability of Wilson currents by storm type and phase. Proc. 15th Int. Conf. on Atmospheric Electricity (ICAE 2014), Normal, OK, IUGG and IAMAS International Commission on Atmospheric Electricity, O-10-02, http:/www.nssl.noaa.gov/users/mansell/icae2014/preprints/ Deierling_77.pdf.

Goodman, S. J., and Coauthors, 2013: The GOES-R Geostationary Lightning Mapper (GLM). Atmos. Res., 125-126, 34-49, https://doi.org/10.1016/j.atmosres.2013.01.006.

Halverson, J., and T. Rickenbach, 2002: Environmental characteristics of convective systems during TRMM-LBA. Mon. Wea. Rev., 130, 1493-1509, https://doi.org/10.1175/1520-0493(2002)130<1493: $\mathrm{ECOCSD}>2.0 . \mathrm{CO} ; 2$.

_ , and Coauthors, 2007: NASA's Tropical Cloud Systems and Processes experiment: Investigating tropical cyclogenesis and hurricane intensity change. Bull. Amer. Meteor. Soc., 88, 867882, https://doi.org/10.1175/BAMS-88-6-867.

Hollinger, J. P., 1991: DMSP Special Sensor Microwave/Imager calibration/validation. Naval Research Laboratory Final Rep., Vol. II, 314 pp.

Hutchins, M. L., R. H. Holzworth, and J. B. Brundell, 2014: Diurnal variation of the global electric circuit from clustered thunderstorms. J. Geophys. Res. Space Phys., 119, 620-629, https:// doi.org/10.1002/2013JA019593.

Israel, H., 1973: Fields, Charges, Currents. Vol. II, Atmospheric Electricity, Probleme der Kosmischen Physik, Vol. 29, Israel Program for Scientific Translations, Ltd., $478 \mathrm{pp}$.

Jayaratne, E. R., C. P. R. Saunders, and J. Hallet, 1983: Laboratory studies of the charging of soft hail during ice crystal interactions. Quart. J. Roy. Meteor. Soc., 109, 609-630, https:// doi.org/10.1002/qj.49710946111.

Kakar, R., M. Goodman, R. Hood, and A. Guillory, 2006: Overview of the Convection and Moisture Experiment (CAMEX). J. Atmos. Sci., 63, 5-18, https://doi.org/10.1175/JAS3607.1.

Kummerow, C., W. Barnes, T. Kozu, J. Shiue, and J. Simpson, 1998: The Tropical Rainfall Measuring Mission (TRMM) sensor 
package. J. Atmos. Oceanic Technol., 15, 809-817, https://doi.org/ 10.1175/1520-0426(1998)015<0809:TTRMMT>2.0.CO;2.

Liu, C., E. J. Zipser, D. J. Cecil, S. W. Nesbitt, and S. Sherwood, 2008: A cloud and precipitation feature database from 9 years of TRMM observations. J. Appl. Meteor. Climatol., 47, 2712 2728, https://doi.org/10.1175/2008JAMC1890.1.

— , E. R. Williams, E. J. Zipser, and G. Burns, 2010: Diurnal variations of global thunderstorms and electrified shower clouds and their contribution to the global electric circuit. J. Atmos. Sci., 67, 309-323, https://doi.org/10.1175/2009JAS3248.1.

_- D. Cecil, and E. J. Zipser, 2011: Relationships between lightning flash rates and passive microwave brightness temperatures at 85 and $37 \mathrm{GHz}$ over the tropics and subtropics. J. Geophys. Res., 116, D23108, https://doi.org/10.1029/ 2011JD016463.

Mach, D. M., R. J. Blakeslee, M. G. Bateman, and J. C. Bailey, 2009: Electric fields, conductivity, and estimated currents from aircraft overflights of electrified clouds. J. Geophys. Res., 114, D10204, https://doi.org/ 10.1029/2008JD011495.

,,--- , and,- 2010 : Comparisons of total currents based on storm location, polarity, and flash rates derived from high-altitude aircraft overflights. J. Geophys. Res., 115, D03201, https://doi.org/10.1029/2009JD012240.

,$- \ldots$, and — 2011: Global electric circuit implications of combined aircraft storm electric current measurements and satellite-based diurnal lightning statistics. J. Geophys. Res., 116, D05201, https://doi.org/10.1029/2010JD014462.

Mansell, E. R., D. R. MacGorman, C. L. Ziegler, and J. M. Straka, 2005: Charge structure and lightning sensitivity in a simulated multicell thunderstorm. J. Geophys. Res., 110, D12101, https:// doi.org/10.1029/2004JD005287.

Markson, R., 2007: The global circuit intensity: Its measurement and variation over the last 50 years. Bull. Amer. Meteor. Soc., 88, 223-241, https://doi.org/10.1175/BAMS-88-2-223.

Mezuman, K., C. Price, and E. Galanti, 2014: On the spatial and temporal distribution of global thunderstorm cells. Environ. Res. Lett., 9, 124023, https://doi.org/10.1088/1748-9326/9/12/ 124023.

Nesbitt, S. W., E. J. Zipser, and D. J. Cecil, 2000: A census of precipitation features in the tropics using TRMM: Radar, ice scattering, and lightning observations. J. Climate, 13, 4087-4106, https://doi.org/10.1175/1520-0442(2000)013<4087: ACOPFI $>2.0 . \mathrm{CO} ; 2$.

Peterson, M. J., 2014: Variations of optical and radio lightning characteristics and the relationship between storm convective intensity and above-cloud electric fields. Ph.D. dissertation, University of Utah, $253 \mathrm{pp}$., https://search.proquest. com/openview/2d481bb6a222ae8958de1016fd602870/1?pqorigsite $=$ gscholar $\& \mathrm{cbl}=18750 \&$ diss $=\mathrm{y}$.

— C. Liu, D. Mach, W. Deierling, and C. Kalb, 2015: A method of estimating electric fields above electrified clouds from passive microwave observations. J. Atmos. Oceanic Technol., 32, 1429-1446, https://doi.org/10.1175/JTECH-D-14-00119.1.

—, W. Deierling, C. Liu, D. Mach, and C. Kalb, 2017: A TRMM/ GPM retrieval of the total mean generator current for the global electric circuit. J. Geophys. Res. Atmos., 122, 10025 10 049, https://doi.org/10.1002/2016JD026336.

Prigent, C., E. Defer, J. R. Pardo, C. Pearl, W. B. Rossow, and J.- P. Pinty, 2005: Relations of polarized scattering signatures observed by the TRMM Microwave Instrument with electrical processes in cloud systems. Geophys. Res. Lett., 32, L04810, https://doi.org/10.1029/2004GL022225.

Reynolds, S. E., M. Brook, and M. F. Gourley, 1957: Thunderstorm charge separation. J. Meteor., 14, 426-436, https://doi.org/ 10.1175/1520-0469(1957)014<0426:TCS >2.0.CO;2.

Rycroft, M. J., R. G. Harrison, K. A. Nicoll, and E. A. Mareev, 2008: An overview of Earth's global electric circuit and atmospheric conductivity. Space Sci. Rev., 137, 83-105, https:// doi.org/10.1007/s11214-008-9368-6.

Saunders, C. P. R., and S. L. Peck, 1998: Laboratory studies of the influence of the rime accretion rate on charge transfer during crystal/graupel collisions. J. Geophys. Res., 103, 13 949-13 956, https://doi.org/10.1029/97JD02644.

- W. D. Keith, and R. P. Mitzeva, 1991: The effect of liquid water content on thunderstorm charging. J. Geophys. Res., 96, 11 007-11 017, https://doi.org/10.1029/91JD00970.

Spencer, R. W., H. G. Goodman, and R. E. Hood, 1989: Precipitation retrieval over land and ocean with the SSM/I: Identification and characteristics of the scattering signal. J. Atmos. Oceanic Technol., 6, 254-273, https://doi.org/ 10.1175/1520-0426(1989)006<0254:PROLAO >2.0.CO;2.

, R. E. Hood, F. J. LaFontaine, E. A. Smith, R. Platt, J. Galliano, V. L. Griffin, and E. Lobl, 1994: High-resolution imaging of rain systems with the Advanced Microwave Precipitation Radiometer. J. Atmos. Oceanic Technol., 11, 849-857, https://doi.org/10.1175/1520-0426(1994)011<0849: HRIORS $>2.0 . \mathrm{CO} ; 2$.

Takahashi, T., 1978: Riming electrification as a charge generation mechanism in thunderstorms. J. Atmos. Sci., 35, 1536-1548, https:// doi.org/10.1175/1520-0469(1978)035<1536:REAACG >2.0.CO;2.

_ , and K. Miyawaki, 2002: Reexamination of riming electrification in a wind tunnel. J. Atmos. Sci., 59, 1018-1025, https://doi.org/ 10.1175/1520-0469(2002)059<1018:ROREIA > 2.0.CO;2.

Toracinta, R., D. Cecil, E. Zipser, and S. Nesbitt, 2002: Radar, passive microwave, and lightning characteristics of precipitating systems in the tropics. Mon. Wea. Rev., 130, 802-824, https://doi.org/ 10.1175/1520-0493(2002)130<0802:RPMALC >2.0.CO;2.

Vivekanandan, J., J. Turk, and V. N. Bringi, 1991: Ice water path estimation and characterization using passive microwave radiometry. J. Appl. Meteor., 30, 1407-1421, https://doi.org/ 10.1175/1520-0450(1991)030<1407:IWPEAC > 2.0.CO;2.

Whipple, F. J. W., 1929: On the association of the diurnal variation of electric potential gradient in fine weather with the distribution of thunderstorms over the globe. Quart. J. Roy. Meteor. Soc., 55, 1-18, https://doi.org/10.1002/qj.49705522902.

— the earth. Geophys. Mem., 7 (68), 1-20.

Wilheit, T., W. Berg, H. Ebrahimi, R. Kroodsma, D. McKague, V. Payne, and J. Wang, 2015: Intercalibrating the GPM constellation using the GPM Microwave Imager (GMI). 2015 IEEE International Geoscience and Remote Sensing Symposium: Proceedings, IEEE, 5162-5165, https://doi.org/10.1109/ IGARSS.2015.7326996.

Williams, E. R., M. E. Weber, and R. E. Orville, 1989: The relationship between lightning type and convective state of thunderclouds. J. Geophys. Res., 94, 13 213-13220, https://doi.org/ 10.1029/JD094iD11p13213.

Wilson, C. T. R., 1921: Investigation on lightning discharges and on the electric field of thunderstorms. Philos. Trans. Roy. Soc. London, 221A, 73-115, https://doi.org/10.1098/rsta.1921.0003. 